\title{
Antioxidants and Their Role in Preventing Diseases: A Review
}

\section{Ekhlas Abdallah Hassan, Wafaa Sh. Al-Zuhairi and Wijdan Amer Ibrahim}

Department of Chemistry, College of Science, University of Diyala, Diyala, Iraq

e-mail: ekhlasbiochemistry@gmail.com

e-mail:Wafaa.chem@gmail.com

e-mail: wijdan.amer84@gmail.com

\begin{abstract}
Antioxidants are natural materials that may delay or stop some kinds of hurt in cells. Many foodstuffs have antioxidants, such as fruits and vegetables. Even though the reactions of oxidation are critical for life, but can also be harmful; vegetation and faunae preserve multifaceted systems of various types of antioxidants, for example, vitamin $\mathrm{C}$, vitamin $\mathrm{E}$, and vitamin $\mathrm{A}$ besides enzymes like superoxide dismutase, catalase and many peroxides. The most important antioxidant source that protected ancient peoples from the harm caused by free radicals was old-style herbal remedies and dietetic diets. In addition, it is broadly utilized in dietetic supplements and have been studied for their potential to prevent diseases such as tumors and coronary heart disease. Although preliminary research suggested that antioxidant supplements could be beneficial to one's health. Furthermore, clinical trials of antioxidant supplements containing beta-carotene, vitamin $\mathrm{A}$, and vitamin $\mathrm{E}$ alone or in various combinations show that supplementation has no effect on the rate or may even increase it. Antioxidants are also used in the food industry as food additives and cosmetics, as well as to prevent rubber and fuel degradation.
\end{abstract}

\section{Introduction}

Antioxidants are critical in the body's defense system against ROS [1]. The antioxidant's physiological job is to protect cellular components from damage caused by free radical chemical reactions. Very good inhibitors for the procedure of oxidation are antioxidants, even at minor concentrations, and thus have various body physiological roles. Antioxidant components in plant material operate as radical scavengers and aid in

Received: January 2, 2022; Accepted: January 19, 2022

Keywords and phrases: antioxidant; vitamin C; vitamin E; vitamin A; enzymes.

Copyright (C) 2022 the authors. This is an open access article distributed under the Creative Commons Attribution License (http://creativecommons.org/licenses/by/4.0/), which permits unrestricted use, distribution, and reproduction in any medium, provided the original work is properly cited. 
the conversion of radicals to less reactive forms. Dietary sources of free radical scavenging antioxidants include fruits, vegetables, and tea, among others. This paper review explains some info about the role of antioxidants in our bodies. Antioxidants are our initial line of protection against free radical risk and are crucial for keeping best health and well-being [2]. Anti-oxidative vegetables and fruit's regular consumption has been documented as decreasing the harm of chronic diseases [3]. According to the research, an antioxidant-rich diet offers a significant long-term health benefit [4]. Citrus fruits, such as oranges and lemons, have a high concentration of natural antioxidants, such as vitamin C. Blueberries, strawberries, grapes, plums, prunes, red beans, spinach, and other fruits and vegetables have been found to be high in antioxidants and have been incorporated into a variety of dietary plans. [5]. According to recent research, fruit-like jackfruit, araticu-domato, pindo palm, and mandacaru-de-tresquinas are excellent providers of vitamins $\mathrm{C}$ and $\mathrm{A}$, as well as phenol compounds [6]. Furthermore, other study investigates genetic, pharmacological, or biological modifications to increase the antioxidant capacity of fruits [7].

\section{Vitamin C}

Vitamin C consumption is contrariwise connected to cancer, having defensive effects for lung, breast, pancreas, stomach, cervix, rectum, and oral cavity cancers [8]. The adrenal glands react by releasing chemicals that trigger the "fight or flight" response. It has been determined that taking 200mg of vitamin C per day can help to lower stress hormone levels. The immune system is hampered by pressure. In both disturbed and relaxed rats, large doses of vitamin $\mathrm{C}$ raise antibody phases that fight germs and viruses, with the calm rat's antibody levels being higher [9]. The chemical structure is shown in Figure 1. 


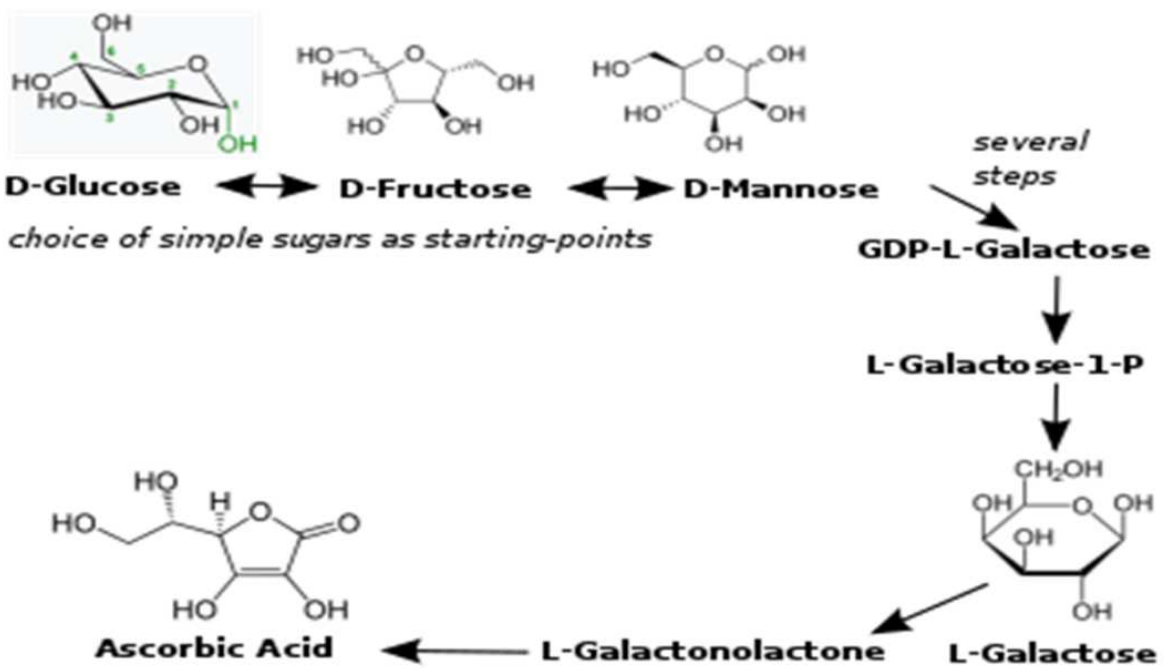

Figure 1: Chemical structure of Vitamin C [9].

\section{Antioxidant activity of vitamin C}

One of the antioxidants is vitamin $\mathrm{C}$. It produces the resonance-stabilized tricarbonyl ascorbate free radical by donating a hydrogen atom $(\mathrm{H} \bullet$ or $\mathrm{H}++\mathrm{e}-)$ to an oxidizing radical [10]. It is possible to reverse the oxidation of vitamin $\mathrm{C}$ to dehydroascorbic acid. Vitamin $\mathrm{C}$ is the primary line of defense, scavenging free radicals before they touch the membrane of the cell. It boasts vitamin E's efficiency. Since vitamin C is an actual Co-antioxidant in vitro for the rebirth of vitamin $\mathrm{E}$ from -tocopherol radicals, it can keep the membrane from peroxidation [11]. Vitamin $\mathrm{C}$ is essential for body of human as it is acting to minor the danger of heart diseases and stopping oxidative harm to mitochondrial DNA. Ascorbate is active against superoxide anion, hydrogen peroxide, hydroxyl radical, and singlet oxygen in preventing damage to the target molecule. Vitamin $\mathrm{C}$, for example, aids in the down regulation of cytokines, protects the endothelium from oxidant stress, and aids in tissue repair, especially during the critical period of COVID-19 [11].

\section{The role of vitamin $\mathrm{C}$ in preventing corona-19}

Figure 2 depicts the proposed processes for vitamin C's amelioration of COVID-19 disease. 


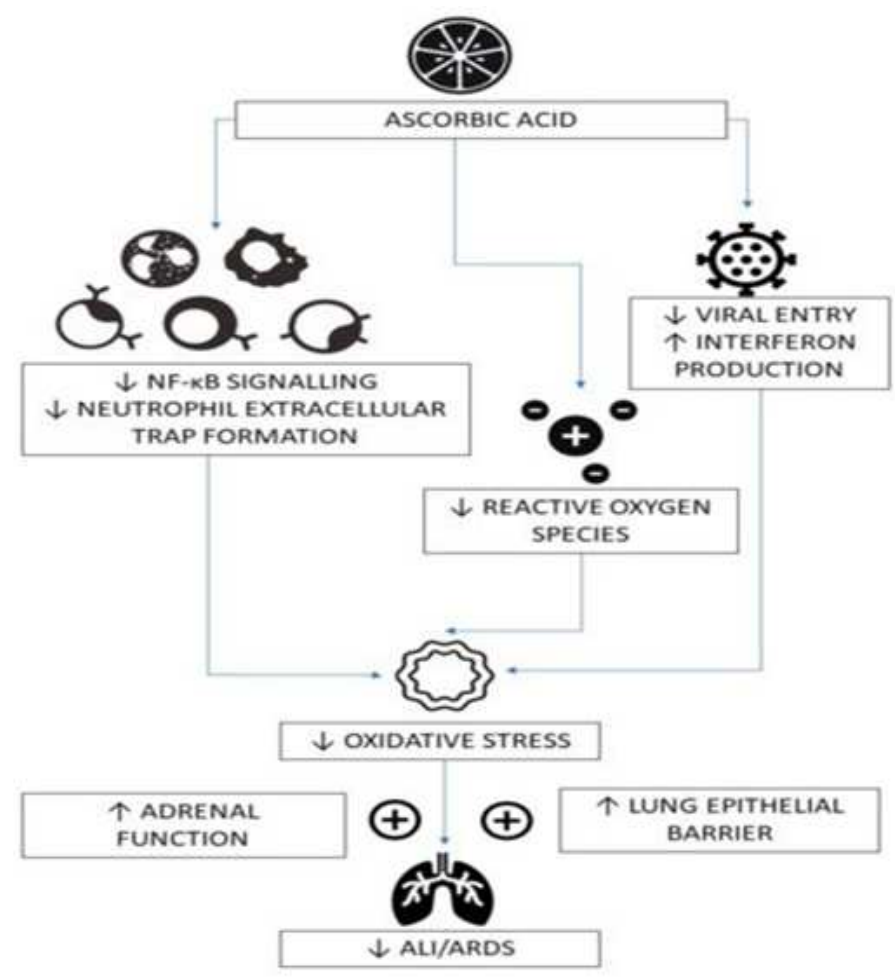

Figure 2: Postulated mechanisms for vitamin C's amelioration of COVID-19 pathology.

\section{Vitamin E}

\section{The role of vitamin $\mathbf{E}$}

Vitamin $\mathrm{E}$ is a lipid-soluble main antioxidant and one of the most important defensive antioxidants [12]. Tocopherols and tocotrienols are naturally occurring tocopherols and tocotrienols. Vitamin E serves as a chain-breaking antioxidant by swiftly transferring its phenolic $\mathrm{H}$-atom to a lipid peroxyl radical and converting it to a vitamin $\mathrm{E}$ radical and a lipid hydroperoxide [13]. Vitamin $\mathrm{E}$ is fat-soluble, meaning it may be stored in fat in the liver and other tissues. Its components (tocopherols and tocotrienols) have been proven to help with anything from anti-aging to sunburn relief. The various roles include maintaining normal cell conditions, skin health, and tissues, protecting red blood cells, antioxidation, and improving immunity. Wheat germ, nuts, seeds, whole grains, green leafy vegetables, vegetable oil, and fish liver oil are all good sources of vitamin E. The chemical structure is shown in Figure 3. 


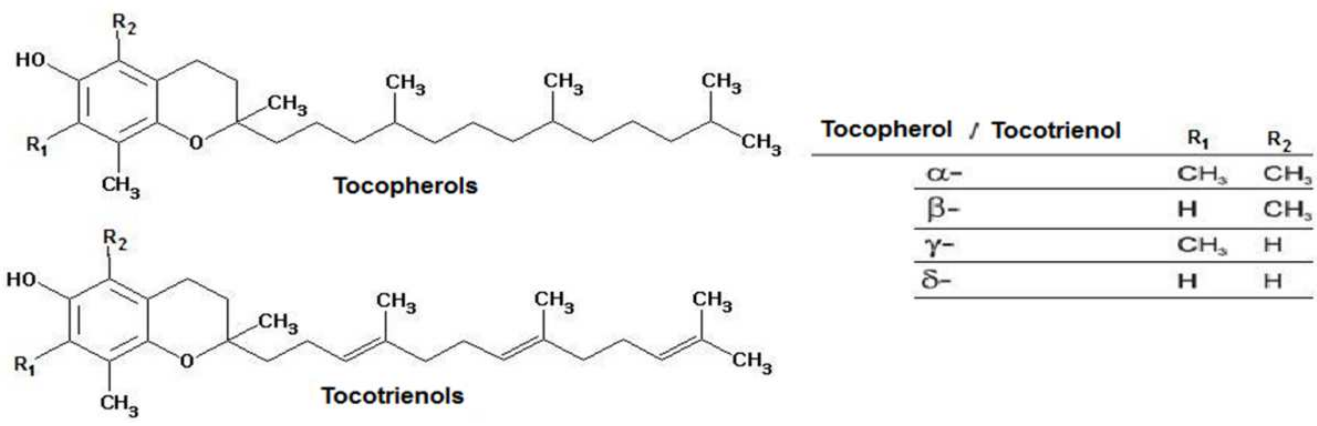

Figure 3: The chemical structure of Vitamin E [28].

Vitamin E is a major antioxidant nutrient [14] that delays cellular old age due to oxidation. Also, it supplies the blood with oxygen thereafter carried to the heart and other organs. Therefore, it reduces tiredness aids in bringing food to cells, supports the capillary walls, and prevents destructive poisons from a red blood cell. Vitamin E inhibits and dissolves calcium deposits and clots of blood in vessels of blood and heart disease, it prevents the sticking of leukocytes to endothelium which promotes stability of plaque. also, $\alpha$-tocopherol prevents the proliferation of smooth muscle cells [15, 30]. Vitamin E acts in the cells through the lipid phase of the membrane. It saves against the toxic radical effect. vitamin E's major function is as an antioxidant stopping the oxidation of nonenzyme cell components (polyunsaturated fatty acids) through free radicals and oxygen. Its action as an antioxidant happens by breaking the chain reaction of free radicals as a result of its ability to transfer hydrogen of phenolic to a proxy free radical of fatty acid polyunsaturated when combined with selenium.

\section{The influence of vitamin $\mathrm{E}$ on male infertility}

Vitamin E has a greater influence on sperm motility [15] as shown in Figure 4. 


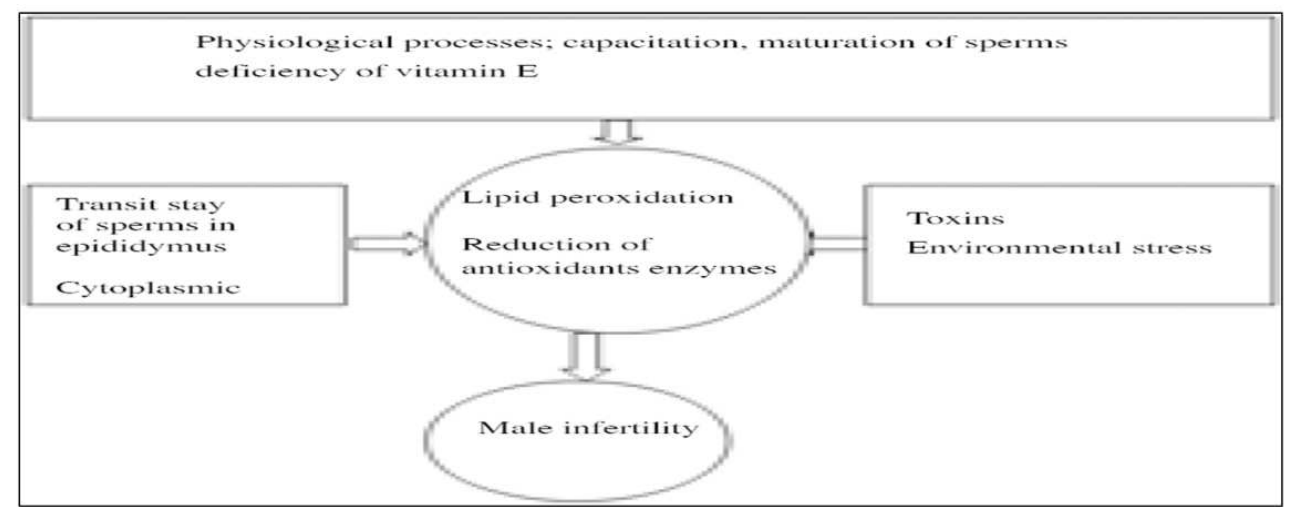

Figure 4: Mechanism of ROS production and infertility [15].

\section{Vitamin A}

Vitamins A described for the first time in 1909 and found to stop night blindness in 1925. Its consists of three active biologically form, retinol, retinal, and retinoic acid. As can be seen in Figure 5 all these compounds of vitamin A contain a trimethyl cyclohexenyl group and an all-transpolyene chain with four double bonds. These compounds can get directly from dietetic sources, as retinyl esters, or from dietary carotenoids (Provitamin A) metabolism [16]. Animal products pigment fruits and vegetables are the main dietary sources for these compounds. The organic solvents can soluble each of these compounds. Retinol or retinal oxidation can be by peripheral cells and it is irreversible: so neither retinal nor retinoic acid is metabolically turned into retinol [17]. 

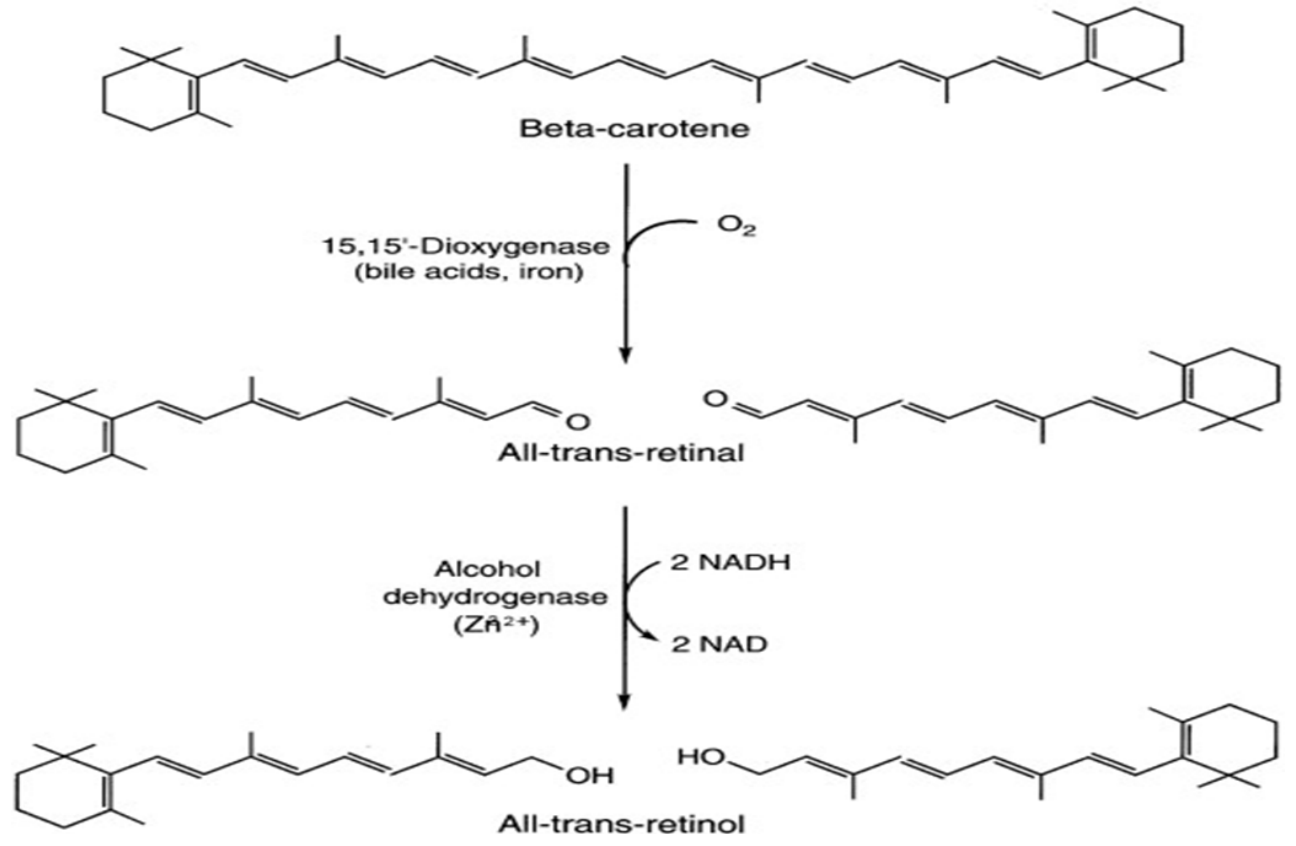

Figure 5: Structures of $\beta$-Carotene and its conversion to Vitamin A derivatives Robert Roskoski, 1996) [16].

The only clearly defined physiological role for retinol is its role in vision. Retinol is oxidized in the rods of the eye to retinal, which, when completed with opsin, forms rhodopsin, allowing dim light vision [18].

\section{Vitamin A and anti-atherosclerosis effects}

Vitamin A has important antioxidant properties which translate into anticancer and anti-atherosclerosis effects [19]. When the partial oxygen pressures are low, the Vitamin A plays a role in catching peroxy free radicals in tissues as shown in Figure 6. The antioxidant ability of retinol is due to the stabilization of free radical's organic peroxide within its conjugated alkyl structure. Since retinol is effective at low concentrations of oxygen [20-22]. 


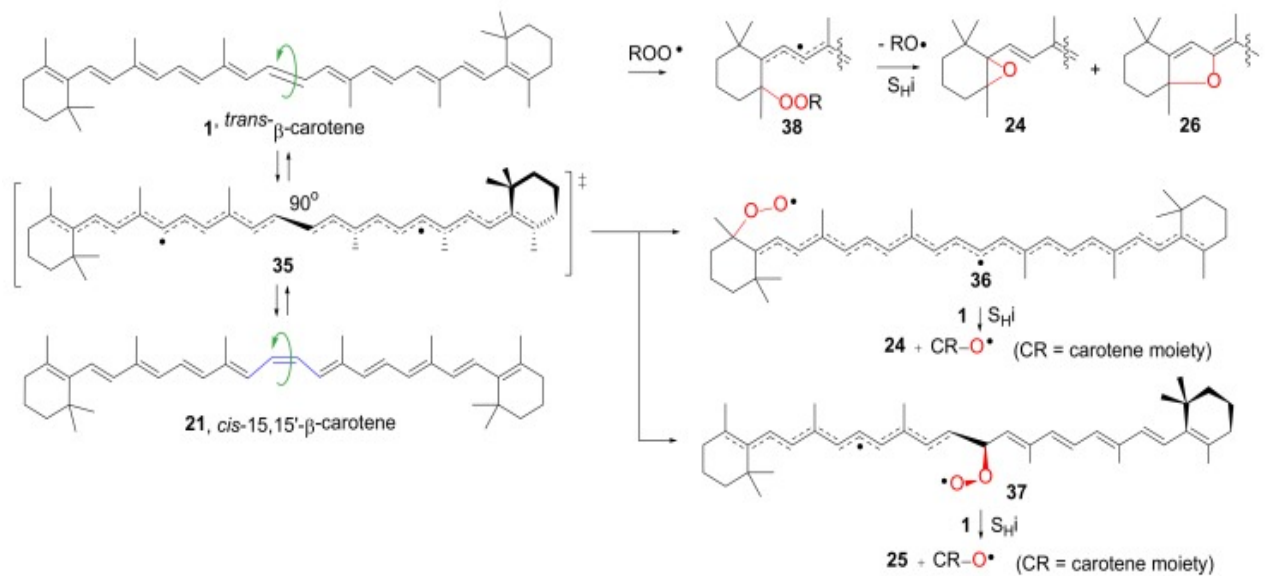

Figure 6: The formation of resonance-stabilized carbon-centered radical from a peroxyl radical and retinol [22].

\section{The Participation of vitamin A in the Visual Cycle:}

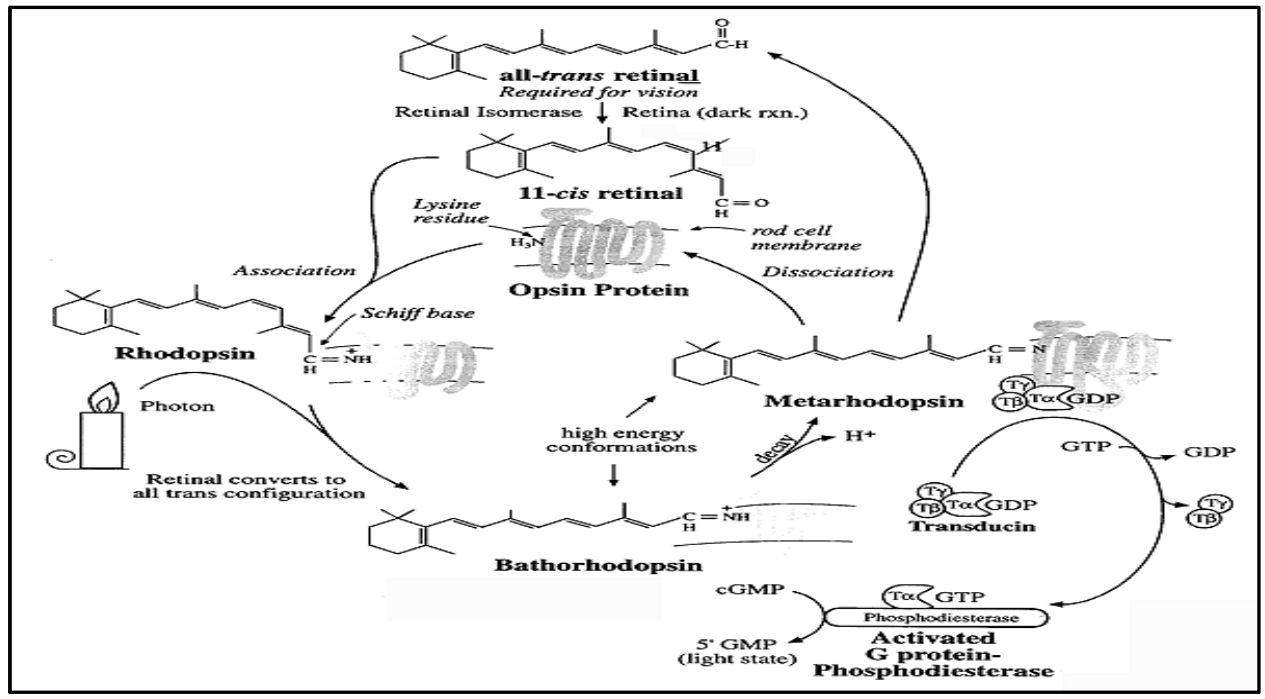

\section{Minerals like Zinc (Zn)}

The zinc role as an antioxidant is not clear. It may be work as a primary antioxidant through the ability to detoxify the generation of free radicals or as a secondary antioxidant through the capacity to reform the damage of free radical components tissue. Zinc's Potential Role in COVID-19 Disease and its Potential Impact on Reproduction as shown in Figure 6 [23]. 


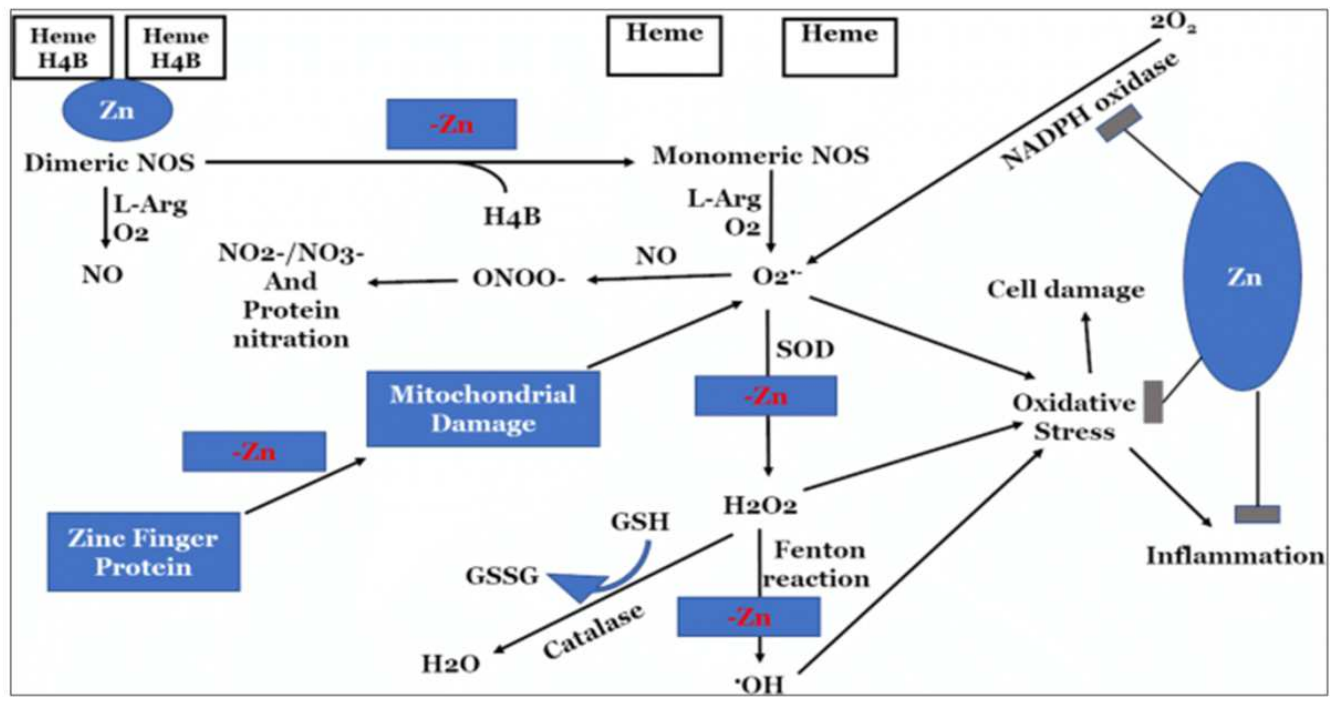

Figure 6: The relationships between NOS, zinc, ROS, and related pathophysiologies.

\section{Enzymes:}

An integrated network of antioxidant enzymes defends cells against oxidative stress [24]. Superoxide is changed to $\mathrm{H}_{2} \mathrm{O}_{2}$ and is after that reduced to $\mathrm{H}_{2} \mathrm{O}$, as a result of procedures such as oxidative phosphorylation. The initial step is catalyzed by superoxide dismutase, and the second step is catalyzed by catalases and other peroxidases, which remove hydrogen peroxide [25].

\section{Superoxide dismutase:}

Superoxide dismutase (SODs) enzymes catalyze superoxide anion to oxygen and hydrogen peroxide conversion [26,27]. About every aerobic cell and extracellular fluid contain SOD enzymes [28]. Centered on the metal cofactor, there are three main forms of superoxide dismutase: $\mathrm{Cu} / \mathrm{Zn}$ (binds both $\mathrm{Cu}$ and $\mathrm{Zn}$ ), iron and manganese (binds either $\mathrm{Fe}$ or $\mathrm{Mn}$ ), and $\mathrm{Ni}$ (binds nickel) [29]. In higher plants, SOD isozymes have been discovered in numerous cell compartments. Mn-SOD is found in mitochondria and peroxisomes. The cytosol, chloroplasts, peroxisomes, and apoplast all contain $\mathrm{Cu}-\mathrm{Zn}$ SOD [30-32]. Fe-SOD is found mostly in chloroplasts, but it is also present in peroxisomes.

People have three different types of superoxide dismutase (as well as all other mammals and most chordates). SOD1 is found in the cytoplasm, SOD2 is found in mitochondria, and SOD3 is found in the extracellular space. Tetramers (four units) are 
first, followed by dimers (two units) (four subunits). Copper and zinc are found in SOD1 and SOD3, while manganese is found in the reactive core of SOD2 [33].

\section{Catalase}

Catalase catalyzes the breakdown of hydrogen peroxide into water and oxygen in almost all living species exposed to oxygen [34]. Hydrogen peroxide is a dangerous byproduct of many normal metabolic processes that must be promptly transformed into less damaging molecules in order to avoid damage. Catalase is a protein that catalyzes the breakdown of hydrogen peroxide into less volatile gaseous oxygen and water molecules in cells. Any known mammal's tissue contains catalase, with the liver having the highest quantity [35,36].

\section{Glutathione systems}

Glutathione, glutathione reductase, glutathione peroxidases, and glutathione Stransferases are all part of the glutathione framework. Animals, insects, and microbes all use this technique [37]. Hydrogen peroxide and organic hydroperoxides are broken down by glutathione peroxidase, a catalytic enzyme. It has four selenium cofactors. Each species has at least four glutathione peroxidase isozymes [37]. The most abundant and efficient hydrogen peroxide scavenger is glutathione peroxidase 1, while glutathione peroxidase 4 is the most active for lipid hydroperoxides. When it comes to lipid peroxides, glutathione S-transferases are very involved. These enzymes are abundant in the liver and are involved in the detoxification process [38].

\section{Protein and Small Molecules like Uric Acid and Albumin}

\section{Albumin}

The liver is synthesized albumin amount that is determined by the total of protein consumed in the food. The level is also subject to the level of plasma feedback regulation. Albumin is created in the liver at a rate that is influenced by nutritional protein consumption and is organized by levels of plasma in a feedback loop. Albumin has an influence on closely all extracellular fluids of the body. Through elimination, a minor amount of albumin lacks from the body. It is catabolized in several tissues and taken up by cells via pinocytosis. Intracellular proteolysis releases the essential amino acids, which are then added to the body pool [39].

\section{Action as an antioxidant of albumin}

The albumin serum level is a significant driver of illness riskiness in pregnancy- 
related hypertension and may be used as a measure for forecasting time to delivery, severe proteinuria, and pregnancy outcomes. Albumin is one of the serum proteins with partial water solubility. Albumin has an antioxidant effect: Due to a large number of charges on each molecule and a large number of molecules available, albumin has a large ligand ability, one of albumin's role is the transport of molecules such as free fatty acids and bilirubin, and this binding property is linked to that role. In the polypeptide albumin site, there is a free thiol group (-SH) and activity. Therefore, it is considered a serious antioxidant to save the body for the negative effect of free radical that causes cell damage through the free radical scavenger. Finally; it is the inhibition of lipid peroxidation [40]. As a result, it is regarded as a serious antioxidant that protects the body from the harmful effects of free radicals that trigger cell damage by acting as a free radical scavenger. Finally, it is lipid peroxidation inhibition [41]. In 1959, bilirubin was proposed as an antioxidant for the first time. Bilirubin can avoid lysosomes from oxidizing at physiologically relevant oxygen concentrations by donating the hydrogen atom attached to the $\mathrm{C}-10$ bridge of the tetrapyrrole molecule to form a carbon-centered radical. Bile, specifically bilirubin, can clean the chain-carrying peroxyl radical [42].

\section{Uric acid}

Purine's final product is uric acid [43]. Metabolic rate Burins obtained by the catabolism of dietary nucleic acid are immediately converted to uric acid. The majority of perinea is excreted in the urine as uric acid, which is formed by the breakdown of endogenous nucleic acids [44,45]. Figure 7 shows the chemical structure.

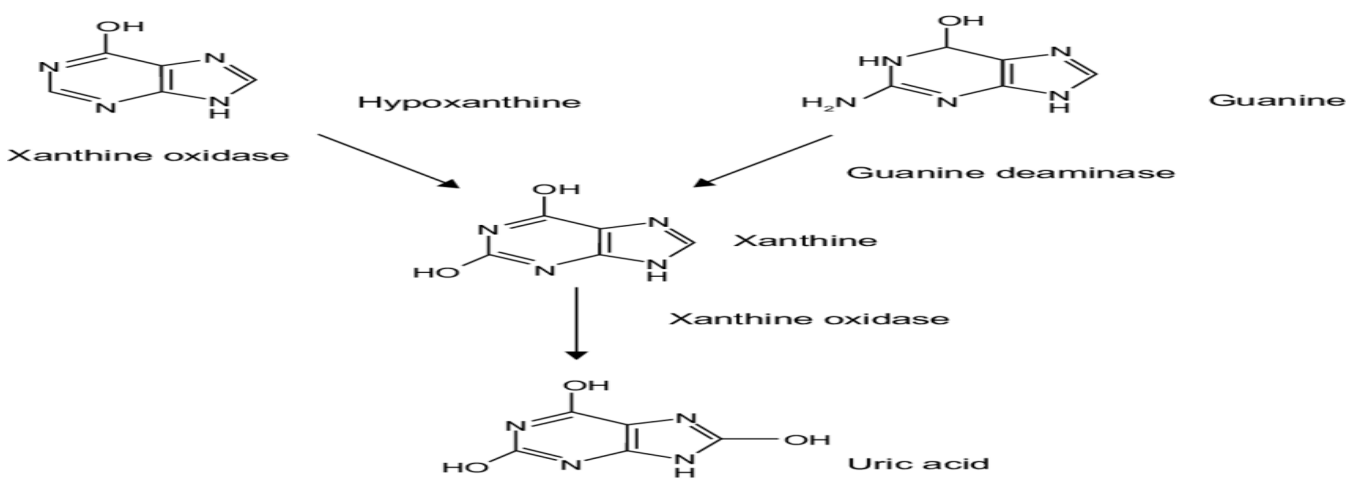

Figure 7: Chemical formation of uric acid [49].

\section{Action as an antioxidant of uric acid:}

Human purine nucleotide metabolism produces uric acid as a byproduct. Purines are 
produced by the breakdown of nucleic acid in ingested meat or synthesized within the body for nucleic acid synthesis. Free uric acid and urate salts are two types of uric acid. At a typical $\mathrm{pH}$ of body fluids, monosodium urate is the type in which uric acid normally occurs, as is any salt of uric acid called the urate [46]. At physiological levels, urate decreases the oxo-heme oxidant produced by the peroxide reaction with hemoglobin, protective erythrocytes from peroxidation harm that leads to lyses [47]. Urate is more readily oxidized by singlet oxygen than deoxynucleotides and is broken by hydroxyl radicals. Urate, together with glutathione, is one of the most essential water-soluble antioxidants in the epithelial fluid. They may have antioxidant roles in the intracellular and extracellular space due to their hydrophobic nature.

\section{The mechanism of antioxidation can be divided into acute and chronic effects:}

\section{Acute effects:}

Generally, acute effects are supposed to include two mechanisms: the decrease in the formation of $\cdot \mathrm{OH}$ from $\mathrm{H}_{2} \mathrm{O}_{2}$ and $\mathrm{O}_{2}$ - and stabilization of protein sulfhydryl [48].

\section{Sulfhydryl stabilization}

One of the acute effects of zinc is an apparent stabilization of sulfhydryls and protection of certain enzyme sulfhydryls, such as aminolevulinate dehydratase, from oxidation [48]. Gibbs et al., recommended that three possibilities account for sulfhydryl groups reactivity stabilization: (1) zinc direct binding to the sulfhydryl; (2) binding zinc to close to the sulfhydryl group in some other protein site which resulting in steric hindrance; or (3) binding to another place on the protein, causing a conformational shift, and a decrease in sulfhydryl reactivity as a result of either of these operations. generally, Acute effects are thought to include two mechanisms: the reduction in the formation of . $\mathrm{OH}$ from $\mathrm{H}_{2} \mathrm{O}_{2}$ and $\mathrm{O}_{2}$ - and stabilization of protein sulfhydryl [53]. In human carotid plaques, protein sulfhydryl is useful for oxidation and mixed-disulfide alterations [49].

\section{Antagonism of redox-active transition metals}

Heart and Chevron observe that zinc has competed actively with Iron and copper in the cellular system of certain site-specific oxidative injury. Through Haber Weiss reaction zinc can antagonize the catalytic properties of these metals' redox-active transition, with esteem to their capacity to promote the formation of $\cdot \mathrm{OH}$ and other free radicals from $\mathrm{H}_{2} \mathrm{O}_{2}$ and superoxide $\left(\mathrm{O}_{2^{-}}\right)$[23]. 


\section{Chronic effects}

Chronic consequences include long-term exposure to zinc, which induces induction of various other compounds, including the metallothioneins, which work as antioxidants in the end [50]. Zinc chronic administration stimulates metallothionein production in a variety of tissues, including the kidney, gut, and liver, according to numerous studies. [51-52]. These metallothioneins had been shown to have antioxidant possessions under the diverse cases, which contain radiation exposure, poisonousnessm from anticancer medications, such as, doxorubicin, and high oxidative pressure circumstances [53]. generally, it had been shown that chronic zinc deficiency cases in increased sensitivity to some oxidative stress and change in membranes of the cells, that resulted in a large increase in the potential for oxidative damage [23].

\section{References}

[1] Boxin, O.U., Dejian, H., Maureen, A.F., \& Elizabeth, K.D. (2002). Analysis of antioxidant activities of common vegetables employing oxygen radical absorbance capacity (ORAC) and ferric reducing antioxidant power (FRAP) assays: a comparative study. J. Agric. Food Chem., 5, 223-228.

[2] Mark Percival (1998). Antioxidants - A review. Clinical Nutrition Insights., Advance Nutrition Publications, 31, 201-205.

[3] Dembinska-Kiec, A., Mykkanen, O., Kiec-Wilk, B., \& Mykkanene H. (2008). Antioxidant phyto-chemicals against type 2 diabetes. British J. Nutri., 99, 109-117. https://doi.org/10.1017/S000711450896579X

[4] Sin, H.P.Y., Liu, D.T.L., \& Lam, D.S.C. (2013). Life style modification, nutritional and vitamins supplements for age-related macular degeneration. Acta Ophthalmologica, 91, 6-11. https://doi.org/10.1111/j.1755-3768.2011.02357.x

[5] Cao, G.H., Russell, R.M., Lischner, N., \& Prior, R.L. (1998). Serum antioxidant capacity is increased by consumption of strawberries, spinach, red wine or vitamin $\mathrm{C}$ in elderly women. J. Nutri., 128, 2383-2390. https://doi.org/10.1093/jn/128.12.2383

[6] Swami, S.B., Thakor, N.J., Haldankar, P.M., \& Kalse, S.B. (2012). Jackfruit and its many functional components as related to human health: A Review. Comprehensive Reviews in Food Sci. and Food Safety, 11, 565-576.

https://doi.org/10.1111/j.1541-4337.2012.00210.x

[7] Gomes, F.S., Costa, P.A., Campos, M.B.D., Tonon, R.V., Couri, S., \& Cabral L.M.C. (2013). Watermelon juice pre-treatment with microfiltration process for obtaining 
lycopene. International J. of Food Sci. and Technol., 48, 601-608.

https://doi.org/10.1111/ijfs.12005

[8] Simon, J.A., Hudes, E.S., \& Tice, J.A. (2001). Relation of serum ascorbic acid to mortality among US adults. J. American. Col. Nutrition, 20, 255-263.

https://doi.org/10.1080/07315724.2001.10719040

[9] Block, G. (1999). Epidemiological evidence regarding vitamin C and cancer. Am. J. Clinical. Nutrition, 54, 1305-1314. https://doi.org/10.1093/ajcn/54.6.1310s

[10] Hossain, M.A., \& Asada, K. (1985). Monodehydroascorbate reductase from cucumber is a flavin adenine dinucleotide enzyme. Journal of Biological Chemistry, 260(24), 129206. https://doi.org/10.1016/S0021-9258(17)38813-0

[11] May, J.M., \& Harrison, F.E. (2013). Role of vitamin C in the function of the vascular endothelium. Antioxidants \& Redox Signaling 19(17), 2068-83.

https://doi.org/10.1089/ars.2013.5205

[12] Handan, M.K., Suleyman, M., \& Yeter, D. (2007). Vitamin status in yearling rams with growth failure. Turkey. J. Veterinary. Animal. Sci. 31, 407-409.

[13] Bashir, M.R., Guido, M.H., Wim, J.F.V., \& Aalt, B. (2004). The extraordinary antioxidant activity of vitamin E phosphate. Bioch. Biophy. Acta, 1683, 16-21. https://doi.org/10.1016/j.bbalip.2004.03.005

[14] Mayes, P.A. (1996). Structure and function of the lipid-soluble vitamins. In R.K. Murray, D.K. Granner, P.A. Mayes, \& V.W. Rodwell (Eds.), Herper's biochemistry (24th ed., pp. 614-24). Connecticut: Appleton and Lange.

[15] Zubair, M. (2017). Effects of dietary vitamin E on male reproductive system. Asian Pacific Journal of Reproduction, 6(4), 145. https://doi.org/10.12980/apjr.6.20170401

[16] Miller, A.P., Coronel, J., \& Amengual, J. (2020). The role of $\beta$-carotene and vitamin A in atherogenesis: evidences from preclinical and clinical studies. Biochimica et Biophysica Acta (BBA)-Molecular and Cell Biology of Lipids, 1865, 158635.

https://doi.org/10.1016/j.bbalip.2020.158635

[17] Chahre, M. (1985). Trigger and amplification mechanisms in visual phototransduction. Annual Review of Biophysics and Biophysical Chemistry, 14(1), 331-60.

https://doi.org/10.1146/annurev.bb.14.060185.001555

[18] Spom, M.B., \& Roberts, A.B. (1983). Role of retinoids in differentiation and carcinogenesis. Cancer Research, 43(7), 3034-40.

[19] Rahi, J.S., Sripathi, S., Gilbert, C.E., \& Foster, A. (1995). Childhood blindness due to 
vitamin A deficiency in India: regional variations. Archives of Disease in Childhood, 72(4), 330-3. https://doi.org/10.1136/adc.72.4.330

[20] Christian, P., West, Jr., K.P., Khatry, S.K., Kimbrough-Pradhan, E., LeClerq, S.C., Katz, J., Shrestha, S.R., Dali, S.M., \& Sommer, A. (2000). Night blindness during pregnancy and subsequent mortality among women in Nepal: effects of vitamin $A$ and $\beta$-carotene supplementation. American Journal of Epidemiology, 152(6), 542-7.

https://doi.org/10.1093/aje/152.6.542

[21] Krinsky, N.I. (1993). Actions of carotenoids in biological systems. Annual Review of Nutrition, 13(1), 561-87. https://doi.org/10.1146/annurev.nu.13.070193.003021

[22] Burton, G.W., \& Ingold, K.U. (1984). Beta-carotene: an unusual type of lipid antioxidant. Science, 224(4649), 569-73. https://doi.org/10.1126/science.6710156

[23] Sethuram, R., Bai, D., \& Abu-Soud, H.M. (2022). Potential role of zinc in the COVID-19 disease process and its probable impact on reproduction. Reproductive Sciences, 29, 1-6. https://doi.org/10.1007/s43032-020-00400-6

[24] Sies, H. (1997). Oxidative stress: oxidants and antioxidants. Experimental Physiology: Translation and Integration, 82(2), 291-5.

https://doi.org/10.1113/expphysiol.1997.sp004024

[25] Ho, Y.S., Magnenat, J.L., Gargano, M., \& Cao, J. (1998). The nature of antioxidant defense mechanisms: a lesson from transgenic studies. Environmental Health Perspectives, 106(suppl 5), 1219-28. https://doi.org/10.1289/ehp.98106s51219

[26] Zelko, I.N., Mariani, T.J., \& Folz, R.J. (2002). Superoxide dismutase multigene family: a comparison of the CuZn-SOD (SOD1), Mn-SOD (SOD2), and EC-SOD (SOD3) gene structures, evolution, and expression. Free Radical Biology and Medicine, 33(3), 337-49. https://doi.org/10.1016/S0891-5849(02)00905-X

[27] Bannister, J.V., Bannister, W.H., \& Rotilio, G. (1987). Aspects of the structure, function, and applications of superoxide dismutas. Critical Reviews in Biochemistry, 22(2), 111-80. https://doi.org/10.3109/10409238709083738

[28] Johnson, F., \& Giulivi, C. (2005). Superoxide dismutases and their impact upon human health. Molecular Aspects of Medicine, 26(4-5), 340-52.

https://doi.org/10.1016/j.mam.2005.07.006

[29] Wuerges, J., Lee, J.W., Yim, Y.I., Yim, H.S., Kang, S.O., \& Carugo, K.D. (2004). Crystal structure of nickel-containing superoxide dismutase reveals another type of active site. Proceedings of the National Academy of Sciences, 101(23), 8569-74. https://doi.org/10.1073/pnas.0308514101 
[30] Corpas, F.J., Barroso, J.B., \& del Río, L.A. (2001). Peroxisomes as a source of reactive oxygen species and nitric oxide signal molecules in plant cells. Trends in Plant Science, 6(4), 145-50. https://doi.org/10.1016/S1360-1385(01)01898-2

[31] Corpas, F.J., Fernández-Ocaña, A., Carreras, A., Valderrama, R., Luque, F., Esteban, F.J., Rodríguez-Serrano, M., Chaki, M., Pedrajas, J.R., Sandalio, L.M., \& del Río, L.A. (2006). The expression of different superoxide dismutase forms is cell-type dependent in olive (Olea europaea L.) leaves. Plant and Cell Physiology, 47(7), 984-94. https://doi.org/10.1093/pcp/pcj071

[32] Cao, X., Antonyuk, S.V., Seetharaman, S.V., Whitson, L.J., Taylor, A.B., Holloway, S.P., Strange, R.W., Doucette, P.A., Valentine, J.S., Tiwari, A., \& Hayward, L.J. (2008). Structures of the G85R variant of SOD1 in familial amyotrophic lateral sclerosis. Journal of Biological Chemistry, 283(23), 16169-77. https://doi.org/10.1074/jbc.M801522200

[33] Chelikani, P., Fita, I., \& Loewen, P.C. (2004). Diversity of structures and properties among catalases. Cellular and Molecular Life Sciences CMLS, 61(2), 192-208. https://doi.org/10.1007/s00018-003-3206-5

[34] Gaetani, G.F., Ferraris, A.M., Rolfo, M., Mangerini, R., Arena, S., \& Kirkman, H.N. (1996). Predominant role of catalase in the disposal of hydrogen peroxide within human erythrocytes. Blood, 87(4), 1595-1599.

https://doi.org/10.1182/blood.V87.4.1595.bloodjournal8741595

[35] Eisner, T., \& Aneshansley, D.J. (1999). Spray aiming in the bombardier beetle: photographic evidence. Proceedings of the National Academy of Sciences, 96(17), 97059. https://doi.org/10.1073/pnas.96.17.9705

[36] Meister, A., \& Anderson, M.E. (1983). Glutathione. Annual Review of Biochemistry, 52(1), 711-60. https://doi.org/10.1146/annurev.bi.52.070183.003431

[37] Brigelius-Flohé, R. (1999). Tissue-specific functions of individual glutathione peroxidases. Free Radical Biology and Medicine, 27(9-10), 951-65.

https://doi.org/10.1016/S0891-5849(99)00173-2

[38] Hayes, J.D., Flanagan, J.U., \& Jowsey, I.R. (2005). Glutathione transferases. Annu. Rev. Pharmacol. Toxicol., 45, 51-88.

https://doi.org/10.1146/annurev.pharmtox.45.120403.095857

[39] Fielding, B.A., Price, D.A., \& Houlton, C.A. (1983). Enzyme immunoassay for urinary albumin. Clinical Chemistry, 29(2), 355-7. https://doi.org/10.1093/clinchem/29.2.355

[40] Young, I.S., \& Woodside, J.V. (2001). Antioxidants in health and disease. Journal of Clinical Pathology, 54(3), 176-86. https://doi.org/10.1136/jcp.54.3.176 
[41] Temme, E.H., Zhang, J., Schouten, E.G., \& Kesteloot, H. (2001). Serum bilirubin and 10year mortality risk in a Belgian population. Cancer Causes \& Control, 12(10), 887-94. https://doi.org/10.1023/A:1013794407325

[42] Stocker, R., Yamamoto, Y., McDonagh, A.F., Glazer, A.N., \& Ames, B.N. (1987). Bilirubin is an antioxidant of possible physiological importance. Science, 235(4792), 1043-6. https://doi.org/10.1126/science.3029864

[43] Newman, D.J., \& Price, C.P. (1999). Renal function and nitrogen metabolism. In C.A. Brutis, \& E.R. Ashwood (Eds.), Tietz textbook of clinical chemistry (pp. 1204-64). WB Saunders, Philadelphia.

[44] Murray, K., Rodwell, V., Bender, D., Botham, K.M., Weil, P.A., \& Kennelly, P.J. (2009). Harper's illustrated biochemistry (vol. 28). New York: McGraw-Hill.

[45] Alderman, M.H., Cohen, H., Madhavan, S., \& Kivlighn, S. (1999). Serum uric acid and cardiovascular events in successfully treated hypertensive patients. Hypertension, 34(1), 144-50. https://doi.org/10.1161/01.HYP.34.1.144

[46] Kaur, H., \& Halliwell, B. (1990). Action of biologically-relevant oxidizing species upon uric acid. Identification of uric acid oxidation products. Chemico-biological Interactions, 73(2-3), 235-47. https://doi.org/10.1016/0009-2797(90)90006-9

[47] Torun, A.N., Kulaksizoglu, S., Kulaksizoglu, M., Pamuk, B.O., Isbilen, E., \& Tutuncu, N.B. (2009). Serum total antioxidant status and lipid peroxidation marker malondialdehyde levels in overt and subclinical hypothyroidism. Clinical Endocrinology, 70(3), 469-74. https://doi.org/10.1111/j.1365-2265.2008.03348.x

[48] Tammy, M., William, B., \& Bettger, J. (1990). The physiological role of zinc as an antioxidant free radical. Biol. Med., 8, 281-91.

https://doi.org/10.1016/0891-5849(90)90076-U

[49] Lepedda, A.J., Zinellu, A., Nieddu, G., Zinellu, E., Carru, C., Spirito, R., Guarino, A., De Muro, P., \& Formato, M. (2013). Protein sulfhydryl group oxidation and mixed-disulfide modifications in stable and unstable human carotid plaques. Oxidative Medicine and Cellular Longevity, 2013, Art. ID 403973, 8 pp. https://doi.org/10.1155/2013/403973

[50] Kägi, J.H., \& Hunziker, P. (1989). Mammalian metallothionein. Biological Trace Element Research, 21(1), 111-8. https://doi.org/10.1007/BF02917243

[51] Swerdel, M.R., \& Cousins, R.J. (1982). Induction of kidney metallothionein and metallothionein messenger RNA by zinc and cadmium. The Journal of Nutrition, 112(4), 801-9. https://doi.org/10.1093/jn/112.4.801 
[52] Menard, M.P., McCormick, C.C., \& Cousins, R.J. (1981). Regulation of intestinal metallothionein biosynthesis in rats by dietary zinc. The Journal of Nutrition, 111(8), 1353-61. https://doi.org/10.1093/jn/111.8.1353

[53] McCall, K.A., Huang, C.C., \& Fierke, C.A. (2000). Function and mechanism of zinc metalloenzymes. The Journal of Nutrition, 130(5), 1437S-46S.

https://doi.org/10.1093/jn/130.5.1437S 